Revista Mídia e Cotidiano ISSN: 2178-602X

Artigo Seção Livre

Volume 15, Número 3, set./dez. de 2021

Submetido em: 20/07/2021

Aprovado em: 24/09/2021

\title{
Enquadramentos e desinformação sobre vacina contra COVID-19 no YouTube: embaralhamentos entre ciência e negacionismo
}

\section{Framings and misinformation about COVID-19 vaccine on YouTube: scrambles between science and denial}

\section{Encuadres y desinformación sobre la vacuna COVID-19 en YouTube: revueltas entre ciencia y negación}

\author{
Luisa MASSARANI ${ }^{1}$ \\ Márcia Cristina Rocha COSTA ${ }^{2}$ \\ Antonio BROTAS ${ }^{3}$
}

\begin{abstract}
Resumo
Este estudo analisa os enquadramentos (framing) e sua relação com a desinformação sobre vacinas contra a COVID-19 em 50 vídeos postados no YouTube em 2020, em canais de influenciadores brasileiros, selecionados a partir do engajamento, considerando visualizações, comentários e likes. Como caminho teórico-metodológico, adota-se a ideia de quadros (frames) como "pacotes interpretativos" que produzem sentidos e têm ressonância na cultura. Os resultados apontam que os quadros "risco e incerteza científica" e "política pública e estratégia política", apesar de subordinados ao frame dominante "novo desenvolvimento tecnológico", foram os mais associados à ocorrência da desordem informacional em narrativas de médicos, religiosos, youtubers e profissionais da comunicação. A desinformação presente nos discursos antivacina também ocorre em narrativas que defendem a ciência e a vacina, evidenciando as tensões e/ou ambiguidades que podem ocorrer no enquadramento midiático. O frame "novo desenvolvimento tecnológico" foi predominante na amostra e no enfrentamento à
\end{abstract}

1 Coordenadora do Instituto Nacional de Comunicação Pública da Ciência e Tecnologia (INCT-CPCT). Professora do Mestrado em Divulgação da Ciência, Tecnologia e Saúde da Casa de Oswaldo Cruz, Fundação Oswaldo Cruz (Fiocruz), do Programa de Pós-graduação Stricto sensu em Ensino em Biociências e Saúde do Instituto Oswaldo Cruz/Fiocruz e do Programa de Pós-graduação Stricto sensu em Educação, Difusão e Gestão em Biociências da UFRJ. Doutora em Educação, Gestão e Difusão em Biociências pela Universidade Federal do Rio de Janeiro. Bolsista produtividade do CNPq 1B. Cientista do nosso estado da Faperj. E-mail: luisa.massarani8@ gmail.com. ORCID: 0000-0002-5710-7242.

2 Professora adjunta do curso de Comunicação Social/Jornalismo da Universidade Federal do Recôncavo da Bahia (UFRB). E-mail: marciarocha.jor@gmail.com. ORCID: 0000-0002-9455-843X.

3 Professor do Mestrado em Divulgação da Ciência, Tecnologia e Saúde da Casa de Oswaldo Cruz, Fundação Oswaldo Cruz (COC/Fiocruz), pesquisador do Instituto Nacional de Comunicação Pública da Ciência e Tecnologia (INCT-CPCT), jornalista e assessor de comunicação da Fiocruz Bahia. E-mail: antonio.brotas@fiocruz.br. ORCID: 0000-0001-8438-2445. 


\title{
míiA
eCOti
DiAno
}

desinformação, destacando-se narrativas de pesquisadores e divulgadores da ciência, que demonstram a importância da divulgação científica.

Palavras-chave: Desinformação. Vacina contra Covid 19. Enquadramento.

\begin{abstract}
This study analyzes framing and its relationship with misinformation in 50 videos from Brazilian influencers about COVID-19 vaccines posted on YouTube in 2020, selected from the engagement, considering views, comments and likes. As a theoreticalmethodological path, the idea of frames is adopted as "interpretatives packages" that produce meanings and have resonance in culture. The results show that the frames 'Risk and Scientific Uncertainty' and 'Public Policy and Political Strategy', although subordinated to the dominant frame 'New Technological Development', were the most triggered in the occurrence of informational disorder in the narratives of doctors, religious, YouTubers and communication professionals. The misinformation present in anti-vaccine discourses also occurs in narratives that defend science and the vaccine, highlighting the tensions and/or ambiguities that can occur in the media framework. The 'New Technological Development' frame was predominant in the sample and in the fight against misinformation, highlighting the narratives of researchers and science disseminators, which demonstrate the importance of scientific dissemination.
\end{abstract}

Keywords: Misinformation. Vaccine against COVID-19. Framing.

\section{Resumen}

Este estudio analiza los encuadres y su relación con la desinformación en 50 videos de influencers brasileños sobre las vacunas COVID-19 publicados en YouTube en 2020, seleccionados del compromiso, considerando las visualizaciones, los comentarios y los 'me gusta'. Como camino teórico-metodológico, se adopta la ideia de los encuades como "paquetes interpretativos"que producen significados y tienen resonancia en la cultura. Los resultados muestran que los encuadres 'Riesgo e Incertidumbre Científicos' y 'Política Pública y Estrategia Política', aunque subordinados al marco dominante 'Nuevo Desarrollo Tecnológico', fueron los más desencadenados en la ocurrencia de desorden informacional en las narrativas de médicos, religiosos, youtubers y professionales de la comunicación. La desinformación presente en los discursos antivacunas también se da en narrativas que defienden la ciencia y la vacuna, destacando las tensiones y/o ambiguedades que puden darse en el encuadre mediático. El encuadre del 'Nuevo Desarrollo Tecnológico' predominó en la muestra y en la lucha contra la desinformación, destacando las narrativas de investigadores y divulgadores de la ciencia, que demuestran la importancia de la divulgación científica.

Palabras-clave: Desinformación. Vacuna contra COVID-19. Encuadres. 


\section{míDiA

\section{Introdução}

A expectativa em torno da descoberta de uma vacina contra a COVID-19 movimentou os debates dentro e fora dos laboratórios, ampliando a participação da sociedade que, inserida no contexto veloz das mídias sociais, produziu conteúdos tanto favoráveis quanto prejudiciais à saúde pública. No imbricamento entre informações corretas, erradas, imprecisas e enganosas disseminadas em plataformas digitais, como o YouTube, a "desordem informacional" (WARDLE; DERAKHSHAN, 2017) aponta a complexidade de um fenômeno que faz habitar, numa mesma narrativa, a defesa da ciência e da vacina com o negacionismo científico.

Diante da produção acelerada de novas tecnologias da saúde, a desinformação desencadeia sentimentos de medo, insegurança e desconfiança em relação à vacina, considerada a única solução possível para o retorno de uma relativa normalidade. A hesitação se agrava quando a disseminação de desinformação está relacionada a falhas no planejamento de políticas públicas, que dificultam a vacinação em massa da população, mesmo o Brasil dispondo de um bem-sucedido Programa Nacional de Imunizações (PNI). A associação da vacina com a ideia de ameaça à saúde ou de disputa política pode trazer consequências ainda maiores quando é espalhada por mediadores com poder de influenciar um grande número de seguidores na decisão de tomar ou recusar a vacina.

Neste estudo, analisamos os enquadramentos e sua relação com a desinformação em 50 vídeos de influenciadores em português do Brasil, publicados no YouTube em 2020, a partir de uma coleta realizada com os termos "vacina" e "COVID" presentes nos títulos ou na descrição dos vídeos. De cunho qualitativo, a pesquisa segue pressupostos dos estudos de framing que compreendem os quadros como parte da cultura (VAN GORP, 2007; REESE, 2007), e como "pacotes interpretativos" (GAMSON; MODGLIANI, 1989) que funcionam como molduras. A identificação dos quadros sinaliza os sentidos interpretativos mais associados à ocorrência de desinformação, expondo incoerências, contradições internas no discurso e estratégias narrativas de diferentes perfis de influenciadores. 
Ciência e sociedade: os desafios da desinformação

Diferente do negacionismo (SCUDELLARI, 2010), a corrente dos Estudos Sociais da Ciência refuta a representação dominante de um conhecimento científico como resultado de observação de fenômenos tais como são, sem a interferência humana interna ou externa, apenas com base em lógicas, experimentações, racionalidades. Em ambientes de tensões e conflitos sociais, políticos, ambientais e culturais, o caráter humano, social e histórico sobre a prática científica redireciona e traz outras perspectivas na conformação e estabilização dos seus objetos, considerando que esses aspectos são inerentes à produção científica dentro e fora dos laboratórios. (LATOUR; WOOLGAR, 1997). Com a pandemia de COVID-19, esses lugares sofreram novos deslocamentos, em função da entrada em cena das narrativas contestatórias ou divisionistas da importância da autoridade cientifica sobre esses objetos. Atores alheios aos métodos, procedimentos e modos de produção de conhecimento científico, como políticos, reivindicam para si autoridade para falar sobre a COVID-19, disputando narrativas sobre a gravidade da doença, as formas de prevenção e até mesmo indicando terapêuticas (USCINSKI et al., 2020).

Para compreender o cenário científico em que emergiu a disputa pela vacina contra a COVID-19, adotamos alguns direcionamentos dos Estudos Sociais da Ciência, compreendendo que o conhecimento científico ultrapassaria os limites dos laboratórios e envolveria uma série de agentes, políticas, tecnologias, numa rede heterogênea que consolidam as "invenções". O conhecimento é corporificado em várias formas materiais e, no contexto de desenvolvimento de vacinas para COVID-19, os laboratórios são centros estratégicos na produção de fatos científicos, de onde sai a matéria-prima que vai municiar as redes e fontes de informação sobre os imunizantes (LATOUR, 2000).

As narrativas antivacina e o trabalho de diferentes produtores de conteúdo, principalmente da divulgação científica, para mitigá-las, também compõem o labirinto que se formou em torno da desordem informacional. Diante das dúvidas e desconfianças que o fenômeno de desinformação provoca em torno da pandemia e da vacina, destacase o esforço de cientistas, instituições de pesquisa, organismos multilaterais de ciência e tecnologia, meios de comunicação e indivíduos espalhados nas mídias sociais para comunicar a ciência. Como contraponto, há uma avalanche de informações falsas, 
enganosas, distorcidas, as quais, em conjunto com as informações de qualidade, configuraram o que a Organização Mundial da Saúde (OMS) definiu como infodemia o excesso de informações que se espalham como um vírus numa crise sanitária, impactando a saúde pública (ZAROCOSTAS, 2020).

A desinformação não é um fenômeno novo, mas a ubiquidade do digital potencializou sua produção e circulação, tornando-se uma ameaça ao pleno funcionamento da democracia. As eleições presidenciais estadunidenses de 2016 foram impulsionadoras para que a desinformação ganhasse maior atenção também entre pesquisadores de diferentes áreas como comunicação, política e ciências sociais, principalmente lançando mão de um termo correlato, fake news, expressão associada à produção e distribuição de informações que simulam o conteúdo noticioso dos veículos jornalísticos tradicionais sem, no entanto, seguir as normas editoriais de precisão, verdade e veracidade, e com o fim de obter vantagens políticas ou econômicas (FREELON; WELLS, 2020).

Neste estudo, adotamos o termo "desinformação" por oferecer uma melhor compreensão da desordem informacional sintetizada nos discursos de mediadores sobre vacina que não tiveram como principal estratégia discursiva disseminar informações falsas para parecerem verdadeiras, a partir da estrutura simbólica que caracteriza a credibilidade do jornalismo. Wardle e Derakhshan (2017) apostam no conceito de desordem informacional e utilizam os seguintes termos para caracterizá-lo: misinformation, que diz respeito à disseminação de informações erradas, sem intenção de causar dano; dis-information, quando o compartilhamento de informações falsas é intencional; e malinformation, que se refere a uma informação baseada na realidade, mas usada de forma maliciosa para causar danos à imagem de alguém, de uma instituição ou país. Além de apresentarem uma concepção que considera níveis de acurácia e intencionalidades, os autores debatem a criação, a produção e a distribuição da desinformação no ecossistema midiático, observando três elementos: o agente, que produz a desinformação e tem uma audiência potencial, de acordo com motivações financeiras, políticas, sociais ou de prestígio pessoal; a mensagem e o grau de acurácia das informações ali contidas, os aspectos legais dos discursos e durabilidade deste conteúdo destinado a uma audiência que deseja influenciar, bem como a presença de 
assinaturas ou marcas falsas de instituições para parecer algo de credibilidade; e o intérprete, que, ao receber a mensagem, pode ignorar ou compartilhar, aderindo ou se opondo à ideia do mediador.

No âmbito da ciência e da saúde, a desinformação pode ser compreendida como informação que se opõe ao consenso epistêmico vigente em uma comunidade científica (SWIRE-THOMPSON; LAZER, 2020), e um dos caminhos utilizados para sua identificação seria mediante o consenso correto ou incorreto adotado pelos especialistas. Vraga e Bode (2020) defendem que há um limite nessa estratégia, bastante utilizada pelas agências de checagem, e apontam dois problemas: a definição de quem seria o especialista, uma vez que os disseminadores de desinformação geralmente acionam falsos especialistas para legitimar seus conteúdos; e a falta de consenso dos especialistas em questões emergentes, como a crise sanitária provocada pelo Zika Vírus nos anos de 2015 e 2016. As autoras propõem que a definição da desinformação migre dos especialistas para as melhores evidências disponíveis no momento, principalmente quando não há consenso.

\section{Vacinas em contexto de pandemia e desinformação}

A demora ou ausência em relação à definição de um quadro conceitual e técnico estabilizado sobre o SARS-CoV-2 - da profilaxia aos sintomas e formas de tratamento gerou ansiedade e medo de morte na população, principalmente nos primeiros meses da pandemia. O pouco conhecimento desenvolvido até então era alvo constante de campanhas de desinformação, que funcionavam em uma lógica global, com adesão facilitada pelas crenças negacionistas sobre mudanças climáticas, movimentos antivacina, racistas e extremistas (BALL, 2020). Enders (et al., 2020) identificaram que a promoção partidária de teorias da conspiração, como a do exagero no número de mortes por COVID19 e a do vírus como arma biológica, é capaz de promover maior adesão do que a informação sobre o tratamento e transmissibilidade da COVID-19. Figuras partidárias, a exemplo do ex-presidente estadunidense Donald Trump e seus seguidores, foram decisivas no caso da hidroxicloroquina ao estimularam a desconfiança nos cientistas e especialistas. No Brasil, a desinformação como arma política também ocorreu com a participação do atual presidente, Jair Bolsonaro, seja na defesa do uso da 
cloroquina/hidroxicloroquina ou no desestímulo ao isolamento social, contrariando recomendações de especialistas e organizações de saúde para prevenir a propagação do vírus (RICARD; MEDEIROS, 2020).

$\mathrm{Na}$ pandemia de COVID-19, as vacinas, mesmo quando ainda eram uma possibilidade remota, já se constituíam como um dos principais temas de interesse social, com aumento na participação do debate público. A mobilização de atores para duvidar ou negar a importância, segurança e a efetividade das vacinas antecede a pandemia, aparecendo como um dos principais temas de desinformação em saúde em revisão sistemática realizada por Wang (et al., 2019). A hesitação vacinal, definida pela OMS como o atraso na aceitação ou recusa de vacinas, envolve dimensões que incluem a desconfiança no sistema de saúde e na indústria farmacêutica, assim como fatores socioculturais, políticos e pessoais, que justificariam a recusa ou a opção por esquemas alternativos. As mídias sociais têm se constituído como um dos principais espaços de disseminação de desinformação sobre vacina, com ocorrências importantes nos Estados Unidos, Reino Unido, Itália e Brasil (BROTAS et al., 2021).

Partindo da premissa de que há o embaralhamento de informações corretas e erradas nos vídeos do YouTube, este estudo propõe a identificação dos agentes e dos enquadramentos acionados na ocorrência de desinformação em narrativas de influenciadores sobre a vacina contra a COVID-19. Trata-se de um esforço no sentido de compreender as lógicas que motivam a desordem informacional e suas consequências na comunicação da saúde pública.

\section{Metodologia}

A escolha do YouTube como repositório dos objetos de análise se justifica pelo alcance de mobilização da plataforma. Como espaço de mediação e influência que se tornou o principal site para acessar vídeos, o YouTube tem mais de dois bilhões de usuários logados mensalmente. $\mathrm{O}$ percurso metodológico do estudo nesse ambiente compreende, numa primeira etapa, a coleta automatizada de vídeos sobre vacina postados 
durante o ano de 2020, por meio da linguagem de programação $\mathrm{R}^{4}$, utilizando um código que captou 6.735 vídeos com o termo "vacina". Numa segunda etapa, foram selecionados os vídeos que continham as palavras "coronavírus" e/ou "COVID" nos títulos e/ou nos seus metadados, excluindo vídeos repetidos ou que utilizaram o termo "vacina" como figura de linguagem ou sem conexão com a vacina contra a COVID-19. Do total de 2.216 produções, 718 foram identificadas como narrativas de influenciadores, chegando-se ao corpus de 50 vídeos (em português brasileiro) de 29 influenciadores que alcançaram maior engajamento pela quantidade de visualizações, comentários e likes, reunindo diferentes perfis de influenciadores e vídeos que tiveram de 20 mil a mais de 730 mil visualizações. Apesar de não ser nosso objetivo aprofundar o debate epistemológico sobre o conceito de engajamento e suas diversas noções (GROHMANN, 2018) convém destacar que, para além das métricas que servem como parâmetro no recorte deste estudo, consideramos pertinente a crítica de Bastos (2020) sobre o uso do conceito de engajamento apenas como performance das narrativas midiáticas, uma perspectiva que se alinha ao capitalismo e aos algoritmos das redes sociais, esvaziando os sentidos históricos de ação política e transformação social do termo. As lógicas operacionalizadas nas plataformas digitais, dessa forma, devem ser observadas tomando como premissa o engajamento crítico e a consciência de fazer parte de processos e práticas socioculturais hegemônicas, que formam gostos culturais, políticos e até científicos.

$\mathrm{Na}$ análise qualitativa realizada neste estudo, consideramos que a ideia de framing midiático dialoga com essa percepção crítica, em que os frames (quadros) são "pacotes interpretativos" (GAMSON; MODIGLIANI, 1989) que resultam de um processo de construção social. Os quadros e suas associações requerem a identificação de manifestações discursivas frequentes, sinalizadas por palavras, expressões e argumentos presentes nas narrativas e que salientam aspectos da realidade, como afirma Entman

4 O R (R Core Team, 2016) é um ambiente e linguagem de programação voltado à análise estatística de dados. Algumas das razões que tornam seu uso popular na comunidade científica, sobretudo nas áreas que se debruçam sobre análises quantitativas, são: ser open source, gratuito, de caráter colaborativo, produzir gráficos de boa qualidade, garantir reprodutibilidade, e ter um quantitativo de pacotes que somam mais de 13 mil, com os quais é possível realizar diversas funções, como extração e manipulação de dados, treinamento de modelos de aprendizado de máquina para problemas de predição e classificação (BOLLMANN et al. 2017). 
(1993, p.52), “de tal modo que se promova uma definição particular do problema, interpretação causal, avaliação moral e recomendação de tratamento".

O caminho teórico-metodológico do framing, utilizado em diversas pesquisas em comunicação, política, ciência e tecnologia, principalmente para compreender as disputas que ocorrem em temas controversos, pressupõe que os quadros (frames) são consequência da relação lógica entre os dispositivos de enquadramento e de raciocínio, mas sua identificação não está restrita à frequência de determinados aspectos de um conteúdo. Reese (2001) elenca seis características de um quadro: organização, princípios, persistência, compartilhamento, simbolismo e estrutura. O quadro se organiza a partir das dimensões cultural e cognitiva, envolve um princípio abstrato numa "cadeia de significação", que compreende esquemas de interpretação de produtores de conteúdo, fontes e audiência, é persistente, inserido na rotina produtiva dos profissionais e acionado frequentemente antes de evoluir para novas formas. Os quadros se comunicam por vários dispositivos simbólicos, mas não basta identificar as características visuais e textuais. Eles não são construídos individualmente, mas podem ser encontrados nos códigos, valores e crenças compartilhados na memória coletiva da sociedade (VAN GORP, 2007). Embora tenham caráter persistente, os quadros se movimentam ao longo do tempo, de acordo com a redefinição de posturas dos atores sociais envolvidos numa questão, seja motivada por um novo contexto ou desafios propostos por novos agentes que entram no debate, a partir da articulação de movimentos sociais e/ou políticos. Como envolve um sentido cultural, o frame se manifesta nos textos, nas relações e tensões entre o dito, o silenciado e as ambiguidades (REESE, 2007). Os dispositivos de enquadramento se referem à escolha de palavras, metáforas, exemplos, descrições, argumentos e imagens que se manifestam no conteúdo midiático e, juntos, formam a ideia organizadora central.

Para a pesquisa exploratória, partiu-se da revisão de literatura bibliográfica e do discurso público inerentes ao tema, bem como da verificação direta dos vídeos que compõem a amostra a ser analisada, para a identificação dos dispositivos de enquadramento mais salientes, de modo a verificar a conformidade ou necessidade de adaptação dos quadros de referência, construídos e adotados pelo grupo de pesquisa em estudos anteriores. Desse procedimento resultou a tabela atualizada dos quadros de referência para este estudo, conforme expressos na tabela 1. 
Tabela 1 - Enquadramentos de referência

(continua)

\section{Quadros Descrição dos enquadramentos Dispositivos de enquadramento}

Nova Pesquisa Trata da descrição das bases científicas e médicas das novas pesquisas e

descobertas sobre vacina.

Novo

Desenvolviment

o Tecnológico
Trata do anúncio da aplicação de descobertas, de novas vacinas, e de novos resultados experimentais e de ensaios clínicos.

Impacto da C\&T Trata do impacto que a ciência gera na sociedade e na qualidade de vida (individual e coletiva).

Bioético e/ou jurídico

Controvérsias Científicas

Incertezas Científicas
Trata de princípios éticos e diz respeito a julgamentos entre certo e errado, verdadeiro e falso. Aponta para as fronteiras e os limites, não técnicos, da vacina.

Discute o negacionismo em oposição às evidências científicas. Aborda a verificação de conteúdos falsos disseminados.

Julga a aceitabilidade dos riscos conhecidos.

Destaca posições da bioética. Questiona a obrigatoriedade da vacina com base nas liberdades individuais.

Discute aspectos legais para punir os pais que não vacinam seus filhos.

Coloca em debate a natureza, os valores e condições do humano e da vida.

Tem foco nas controvérsias científicas relacionadas à vacina e vacinação.

Trata o risco como ameaça à saúde do ser humano, para quem é a favor ou
Descoberta, avanço, pesquisa, conhecimento, ciência, cientistas trabalham, cientistas descobriram.

Fase de testes, ensaios clínicos, eficácia, eficiência, resposta imune, produção em massa, melhora da vacina, tem desenvolvido, aumenta a proteção, nova tecnologia, nova vacina, novos resultados clínicos.

Benefícios, melhorias, combate, combater, evitar mortes/surto/doenças, melhoria da saúde, proteger, permitiu viver.

Ético, falso, mentira, não é verdade, enganoso, fake news, punição jurídico, legal, autonomia, liberdade, individual, ECA, Estatuto da Criança e do Adolescente, lei, obrigação, multa, prisão, pena, denúncia, crime, Conselho Regional de Medicina, CRM, exigências, o filho(a) é meu e eu sei cuidar dele, os pais sabem o que é melhor para seus filhos(as), o ECA não vale para a vacina, responsabilidade, eu amo meu filho para dar vacina, eu amo meu filho(a) para não dar vacina, mandado, escolha dos pais.

Controvérsia, controverso, não está estabelecido, debate, discussão, contestar os resultados, cientistas se opõem, lados opostos, lados diferentes.

Risco de doença, risco de morte, efeitos adversos, advertência, riscos, incerteza, insegura, veneno, 
Tabela 1 - Enquadramentos de referência

(continuação)

Incertezas

Científicas

Personalização

Antecedentes/

Background

Científico

Políticas

Públicas e

Estratégia

Política contra a vacinação. Trata da

probabilidade dos efeitos adversos na vacina. Aborda os limites da ciência na produção de conhecimento e as vulnerabilidades na gestão de riscos no presente e no futuro. Indica incertezas sobre as ações de proteção das vacinas e suas consequências sobre a saúde do indivíduo

Tem destaque para algum personagem que faça parte da questão da vacina abordada pela matéria. $\mathrm{O}$ enquadramento aqui é a narrativa pessoal, o depoimento, o testemunho ou a experiência com a vacina.

Trata dos antecedentes científicos gerais da questão. Descrição de pesquisas anteriores, recapitulação dos resultados e conclusões já conhecidas sobre vacina.

Trata das estratégias e disputas de poder em relação à vacina; conflito entre atores políticos, das gestões governamentais sobre a saúde coletiva no quesito do desenvolvimento, produção, distribuição da vacina no Brasil, incluindo a definição públicos prioritários em campanhas e sua cobertura vacinal. Retrata os debates sobre vacina que integram a pauta política dentro e fora do congresso ou proposta por partidos políticos, movimentos sociais e outras organizações da sociedade civil. Trata da desconfiança e descrença com o serviço público. Aborda o resultado de políticas públicas em relação à vacina. Se relaciona com os serviços de saúde disponibilizados nos SUS, como Programa Nacional de Imunização (PNI), a aplicação das vacinas e as campanhas publicitárias do Ministério da Saúde. autismo, autista, contaminação, efeito rebanho, risco coletivo, desproteção, dúvidas sobre eficácia, não sabemos, insegurança, reações, dor, sangramento, hematomas, diarreia, dano, exposição, afetar.

Cidadão, paciente, criança, pais, estudo de caso, voluntários, participante, exemplo, cônjuge, familiares, parente, vítima, me vacinei, minha caderneta está em dia.

Erradicou, resultados anteriores, cronologia da pesquisa, linha do tempo, as primeiras versões, primeiros resultados.

Direito, SUS, Sistema Único de Saúde, posto de saúde, governo, Ministério da Saúde, Bolsonaro, Dória, governo comunista chinês, projeto de lei, campanha de vacinação, calendário vacinal, cobertura vacinal, PNI, Programa Nacional de Imunização, filas, falta de vacina/estoque, estoque, qualidade, acesso, disponibilidade, previsão, distribuição, cidadão, problema de estoque, rede pública, Secretaria Municipal de Saúde, demanda, escalonamento, públicoalvo, público prioritários, OMS, Organização Mundial da Saúde, cartão de vacina, federal, oficial, político, partido, o governo determinou, relatório. 
Tabela 1 - Enquadramentos de referência

(continuação)

Sociocultural e Trata da harmonia com a natureza em vez Ambiental de dominância sobre ela. Aborda o sistema de crenças e doutrinas condicionadas a aspectos religiosos, culturais e sociais. Trata-se de reflexões sobre filosofias alternativas de vida.

Econômico e Tem foco nas pesquisas para ações de mercadológico empresas de biotecnologia. Destaca preços, oportunidades de negócio e competitividade nacional frente aos mercados globalizados; Dá ênfase aos investimentos e possibilidades de retorno para as empresas. Aponta a necessidade de patenteamento. Trata do custobenefício em relação ao gasto privado ou investimento em relação a economia do tesouro nacional.

Caixa Pandora de Trata dos impactos ou catástrofes produzidas pela vacina. Destaca a impossibilidade de controle absoluto sobre esta tecnologia, com possibilidade de criação de monstros (efeito Frankenstein). Dá como certo o retorno negativo em relação às vacinas, uma espécie de fatalismo, do qual a sociedade não pode escapar - seria o preço pelo caminho escolhido.
Social, natural, limpo, vitamina D, orgânico, saudável, vida alternativa, poluir o corpo, eu acredito, vida natural, imunidade natural, vacina natural, fé, religião, pastor, padre, igreja, acreditar, orar, rezar, benção.

Custo, patente, investimento, lucro, mercado, privado, propriedade industrial, custo-benefício, economia da saúde, custoefetividade, economia pública, privatização dos resultados, redução de custo, comércio internacional/local/nacional, importação, compras, venda, bolsa de valores, ações, preço, valor.

Ameaça, catástrofe, redução populacional, extermínio, Bill Gates, interesses, poderosos, controle, não sabemos, cobaias, rebanho, gado, Nova Ordem Mundial, Illuminati, genocídio, verdade, fim dos tempos, vacina contamina, Big Pharma, apocalipse.

Fonte: quadros de referência desenvolvidos no Grupo de Pesquisa Mídias Sociais, Jornalismo e Vacina do INCT-CPCT.

Para mapear os dados dos vídeos tomados como unidade de análise, foi produzido um formulário com o auxílio do Google Forms, no qual foram registradas informações como tempo de duração, número de visualizações, comentários, as categorias temáticas atribuídas aos canais, assim como os responsáveis pela condução da narrativa, o perfil do influenciador, os quadros predominantes e secundários em cada vídeo. O posicionamento dos mediadores em relação às vacinas e à desinformação também foi avaliado. Todas essas variáveis puderam ser cruzadas com o auxílio do Google Data Studio, ferramenta que permite criar relatórios de diferentes bancos de 
dados. Após a identificação dos quadros, optou-se por fazer a correlação entre os frames das narrativas e os sentidos interpretativos presentes nos trechos dos vídeos que disseminaram algum tipo de desinformação, sem a pretensão de operacionalizar o conceito de desordem informacional, pois consideramos que há variáveis que dificultam apontar intencionalidades, embora alguns aspectos tenham sido observados com base nas formulações de Wardle e Derakhshan (2017). Convém ressaltar a característica dinâmica do enquadramento que, como afirma Reese (2007), requer negociação de sentido e depende da ação dos agentes envolvidos nas disputas interpretativas. A ocorrência do quadro não significa que os seus enunciadores tenham o mesmo posicionamento ou as mesmas justificativas para uma questão. Sendo assim, a presença do quadro predominante e suas associações com os quadros secundários foram constatadas tanto em produções de informações confiáveis quanto em narrativas que disseminaram algum tipo de desinformação e/ou imprecisão.

\section{Resultados e discussão}

Do total de 50 vídeos, que acionaram 7.124.876 interações em seu conjunto, 16 (32\%) propagaram algum tipo de desinformação, relacionando a vacina contra a COVID19 a boatos e rumores disseminados nas mídias sociais, como a desconfiança em torno da vacina chinesa, a vacina como marca da besta, a presença de microchip para controle da população ou desconfiança do processo científico. Outros vídeos, principalmente de vozes da medicina, abordaram a defesa da hidroxicloroquina como alternativa de tratamento, a associação da vitamina D à redução de mortes pela COVID-19 e como auxiliar na prevenção do coronavírus, além de interpretações precipitadas de cura sobre uma vacina em desenvolvimento ou ainda a ideia de que, quem já teve a doença, estaria imunizado. Apesar de o frame "novo desenvolvimento tecnológico ter sido acionado em 29 vídeos, sendo predominante em 21 deles (42\% da amostra), a desinformação sobre a vacina contra a COVID-19 se evidencia de forma mais próxima com os frames secundários "risco e incerteza científica" (15 vídeos, 30\%) e "política pública e estratégia política" (10 vídeos, 20\%). 
Figura 2: enquadramentos principal e secundários
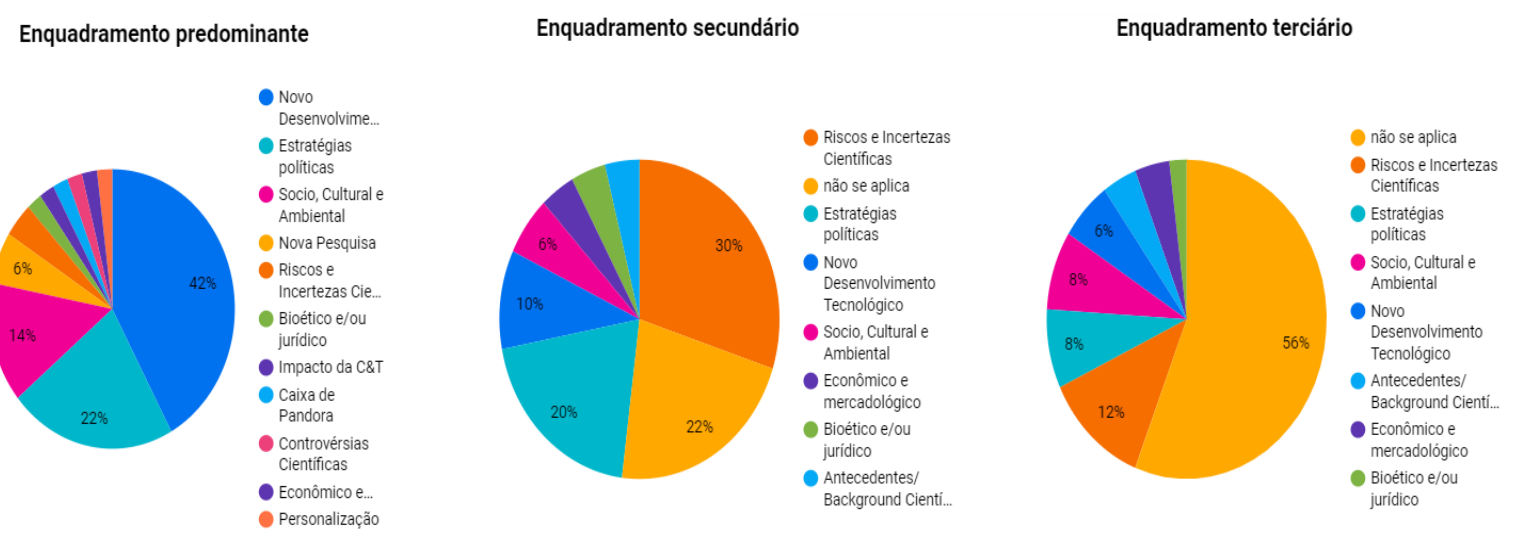

Fonte: elaborado pelos autores (2021).

Os demais frames tiveram baixa ocorrência como enquadramento secundário. Em 12 vídeos (24\%), a narrativa não apresentou associação com um frame secundário. Os frames "personalização', “caixa de Pandora” e "controvérsia científica” apareceram nesse corpus como quadro predominante em um vídeo (2\%) cada um, mas a desinformação só foi constatada no quadro "caixa de Pandora" que, pela própria descrição do quadro, já o associa às teorias conspiratórias de controle da população mundial e catástrofes produzidas pela vacina. O enquadramento "política pública e estratégia política", por sua vez, surge como o principal sentido em 11 vídeos (22\%), enquanto o "risco e incerteza científica" é o quadro predominante em 2 vídeos (4\%). Como enquadramento tangencial nas narrativas, o quadro "política pública e estratégia política" é acionado em 4 vídeos (8\%), enquanto "risco e incerteza" se verifica em 6 vídeos (12\%). No conjunto da amostra, são quadros praticamente equivalentes, considerando o somatório de ocorrências como frame principal e secundários.

Em 43 vídeos (86\% da amostra), a narrativa foi conduzida pelo mediador, enquanto o mediador e o entrevistado comandaram a discussão sobre a vacina em 4 vídeos e a fonte-protagonista em 3 vídeos. Em relação ao perfil do mediador, os médicos lideram a produção de narrativas (14 vídeos), seguidos pelos youtubers divulgadores da ciência (10 vídeos) e youtubers (9 vídeos). Os médicos, pesquisadores e youtubers divulgadores científicos tornaram-se aqueles que mais produziram conteúdo relacionado à vacina no YouTube, dentro do período de análise, sobretudo médicos (28\%), que se fizeram 
presentes no debate de forma mais significativa. Além dos frames "risco e incerteza científica" e "política pública e estratégia política", o fenômeno da desinformação também se manifestou, de forma tangencial, com a ocorrência do frame "sociocultural e ambiental", vinculado à ideia de uma vacina natural contra a COVID-19 e a crenças religiosas; e do frame "bioético e/ou jurídico", que reivindica as liberdades individuais diante da discussão sobre obrigatoriedade de tomar a vacina.

\section{Narrativas e desinformação: enquadramentos da desordem}

No contexto da desinformação, o enquadramento "risco e incerteza científica" só foi acionado como frame principal em narrativas que produziram uma ideia de vacina como ameaça à saúde do ser humano, questionando sua segurança e eficácia, principalmente pela desconfiança do processo científico, por conta do tempo acelerado de produção. Esse sentido ocorreu até mesmo em obras de humor e ficção, voltadas ao entretenimento, como o vídeo "Os signos tomando vacina do covid", postado em 29 de dezembro 2020 pelo canal da youtuber de humor e/ou comédia, Kel Freire, que está entre os 10 vídeos da amostra com maior engajamento (204.024 interações). Ao encenar diferentes personagens e suas reações diante da vacina, a partir das características de cada signo do zodíaco, a narrativa dissemina medo, dúvida e hesitação quando mostra, em sua maioria, cenas de pessoas correndo para não tomar a vacina, entortando a boca ou caindo como simulações de efeitos adversos. Nos papéis de repórter e entrevistada, as personagens representadas pela mediadora desconfiam da vacina em função do tempo de produção, prevalecendo o sentido de risco à saúde, a partir de expressões como "medo", "efeitos colaterais", "morte", como se verifica nos seguintes trechos:

[...] a vacina contra o coronavírus foi produzida rapidamente. Teve pouco tempo de teste, mas já está sendo aplicada. Senhora, a senhora está com medo? [...] Quem me garante que eu não vou tomar e cair aqui durinha? Eu não vou tomar vacina coisa nenhuma (FREIRE, 2020, s. p.).

A ausência de informações baseadas em evidências científicas na construção da narrativa promove uma conexão equivocada entre tempo de produção e qualidade da vacina, que pode ser interpretada como um risco coletivo. Esse, inclusive, é um dos 
principais argumentos de conteúdos que adotam um discurso explicitamente antivacina contra a COVID-19. No vídeo "Vacina covid em menos de 1 ano? Dr. Alessandro Loiola e Fernando Beteti”, publicado em 14 de agosto de 2020, o mediador repercute o anúncio da vacina russa numa entrevista com o médico Alessandro Loiola, cuja especialidade não é informada. A narrativa nega a vacina e a credibilidade da ciência de modo a estimular a hesitação vacinal, o que tende a causar uma desordem de maior impacto quando se trata de uma voz identificada como da medicina. "[...] nenhuma dessas vacinas teve tempo suficiente para cumprir esses protocolos. Então, nenhuma delas dá pra ser considerada segura e eficaz" (BETETI, 2020, s. p.). Em outro vídeo do mesmo canal, "Porque o Brasil é escolhido para testar vacina do COVID? Boletim Repórter Saúde”, publicado em 28 de setembro de 2020, o mediador assume que não vai tomar a vacina e se referencia nas fontes que entrevista, todos com vídeos recomendados pelo canal. Na perspectiva natural de prevenção pelo medo da vacina, o mediador defende o uso de vitamina $\mathrm{D}$ e um tratamento precoce que não existe para a COVID-19.

[...] Eu não vou tomar a vacina. Eu vou manter a minha vitamina D sempre lá em cima, vou fazer o tratamento precoce [...] pra tomar vacina, eu preciso ter certeza absoluta do efeito colateral dela [...] (BETETI, 2020, s. p.).

A correlação entre o enquadramento "política pública e estratégia política" e a desinformação ganha aderência em narrativas que se coadunam a discursos de atores políticos em defesa de medicamento sem evidência científica ou desconfiam da vacina, especialmente a produzida na China. A disputa política ocorre geralmente com a repercussão de declarações do presidente Jair Bolsonaro, um agente frequente de mensagens com potencial antivacinação, as quais descredenciam acordos do país asiático com adversários políticos. No vídeo do canal Doug Vlogs, "URGENTE! LUCIANO HUCK REBATE BOLSONARO BRASILEIROS PRECISAM SABER DISSO SOBRE VACINA COVID!", publicado em 4 de setembro de 2020, as letras em caps lock e a exclamação no título chamam a atenção para o enquadramento "política pública e estratégia política", abordando o conflito entre o presidente e o apresentador da Rede Globo, que criticou Bolsonaro por desestimular a vacinação quando este declarou que ninguém é obrigado a se vacinar. Como estratégia de construção narrativa, o influenciador 
lê um texto noticioso sobre o episódio, convoca sua audiência a opinar e os comentários são exibidos na tela, enquanto alguns são lidos pelo mediador. Apesar da ocorrência de opiniões favoráveis à vacina, a maioria concorda com a posição do influenciador, que reforça a hesitação vacinal presente na declaração do presidente. Em outro vídeo, "URGENTE! BOLSONARO DECLARA ISSO SOBRE VACINA PARA COVID BRASIL PRECISA SABER E DESAFIO AMENDRONTA!", publicado em 29 de dezembro de 2020 no mesmo canal, o mediador, mais uma vez, se alia às declarações do presidente em relação à vacina e propõe uma enquete para saber se a vacina deve ser obrigatória ou não. Os comentários são majoritariamente contrários à vacina produzida pela China, alvo de desconfiança, medo e teorias da conspiração.

A Rosa falou: se for vacina da China não vou tomar [...] E a Maria falou: é a vacina da China comunista que não dá pra confiar [...] A Ilza falou o mesmo que eu falei. Então vai lá e toma primeiro Luciano Huck. Se tomar primeiro, você, Angélica e sua família aí, quem sabe a gente toma também, tá bom? (DOUG VLOGS, 2020, s. p.).

Nas formulações de Wardle e Derakhshan (2017), propostas para análise dos elementos da desinformação, além da acurácia e do agente produtor da mensagem, o intérprete também é um elemento fundamental na circularidade da desordem informativa, uma vez que ele pode compartilhar, aderindo ou não à ideia do emissor que, neste estudo, corresponde ao influenciador, o agente que produz e distribui a mensagem, a partir de uma narrativa individual ou em parceria com uma fonte-protagonista. No exemplo a seguir, a vacinação, enquanto estratégia de controle da pandemia, é refutada pela fonteprotagonista do vídeo, a partir da defesa da hidroxicloroquina como alternativa de tratamento mais segura e eficaz do que a vacina. A voz médica aciona o frame "política pública e estratégia política" para criticar políticos favoráveis à vacinação e fazer conexões entre o medicamento e o sucesso de um suposto tratamento precoce, à revelia das evidências científicas.

[...] É como se você tivesse dois padrões pra poder comparar: eu tenho uma vacina, que foi desenvolvida às pressas, só Deus sabe como, um processo que levaria cinco anos diz que foi feito em oito meses [...] do outro lado do ringue, a gente tem a hidroxicloroquina. Os países que empregaram precocemente o tratamento de hidroxicloroquina, a 
Rússia, por exemplo, teve 105 mortes pra cada milhão de habitantes (BETETI, 2020, s. p.).

A defesa da hidroxicloroquina serve como exemplo da politização que ocorre na desinformação, até mesmo em vídeos de mediadores que transitaram entre a exaltação dos resultados da ciência e o negacionismo científico, configurando um tipo de narrativa protagonizada, principalmente, pelo agente médico.

\section{Embaralhados entre informação e desinformação}

$\mathrm{Na}$ desordem informacional, informações corretas e erradas se misturam em narrativas conduzidas por influenciadores que defendem a vacina, a ciência e até esclarecem dúvidas da sua audiência provenientes de boatos e crenças que circulam pela internet. Esse tipo de narrativa mostra as variáveis que perpassam o fenômeno da desinformação, aliado a discursos de fé, religião, medicina natural e política. Nesse grupo de vídeos, o quadro "política pública e estratégia política" foi o que mais se relacionou com a desinformação, apesar do registro de ocorrências com os frames "risco e incerteza científica" e "sociocultural e ambiental".

Embora vídeos de perfil médico tenham sido mais frequentes nesse embaralhamento, o vídeo de maior engajamento da amostra "ISRAEL DESCOBRIU A CURA PARA O CORONAVÍRUS? | Anticorpo e Vacina |" é do pastor Lamartine Posella, publicado em 7 de maio 2020, ainda no início da pandemia. O frame "política pública e estratégia política" é sinalizado desde o título em caps lock, para exaltar o sucesso de Israel enquanto nação que inspira muitos religiosos. A conexão equivocada ocorre ao associar a cura da COVID-19 a uma vacina que os cientistas ainda estavam tentando desenvolver e que, na verdade, serve para prevenção e não para tratamento e/ou cura da doença.

[...] quando você fala que descobriu o anticorpo, você descobriu a cura, né? Porque o anticorpo combate a doença. É isso que a vacina faz [...] Mais uma vez, bater palma pro povo judeu, que povo extraordinário, que povo abençoado (POSELLA, 2020, s. p.).

A criação, produção e distribuição de um conteúdo por um determinado tipo de agente, como é o caso desse mediador religioso, busca conexão com um grupo de pessoas 
motivadas pelas crenças e organizadas por interesses comuns. O engajamento de 778.854 mil interações, maior entre todos os vídeos da amostra, aponta a capacidade de disseminação de interpretações erradas pelo público potencial de um agente da desinformação, ainda que haja ou não intenção de causar danos. Assim como a empolgação por uma benção não se concretiza em fato científico, o mesmo ocorre com narrativas que, contraditoriamente, são aliadas da vacina, exaltam as boas notícias da ciência, mas se desvinculam das melhores evidências científicas na defesa de suas opiniões. As produções do canal Dr. Marcelo Lima, que se apresenta como médico e homem de fé, somam oito vídeos no conjunto da amostra; em seis deles observamos a relação imbricada entre informações corretas, informações sem validação da comunidade científica e combate à desinformação, o que pode ocorrer numa mesma narrativa.

Na live "Coronavírus - nova vacina em teste", realizada no dia 24 de abril, o médico aborda com otimismo o desenvolvimento de uma vacina, principalmente aquela vinda de Israel, faz a defesa da hidroxicloroquina como medicamento para tratamento da COVID-19 e desmente a relação entre COVID-19 e vídeos falsos disseminados no início da pandemia, segundo os quais chineses estariam morrendo no meio da rua. Em outro vídeo, "Coronavírus - vacina oral tem data para começar, publicado em 12 de abril 2020, o mediador, na interação com sua audiência, combate a desinformação de que chá de boldo serve para evitar COVID-19 e, mais uma vez, defende a hidroxicloroquina como alternativa enquanto não há vacina, ao ler o comentário de um seguidor. A interação evidencia a adesão do seguidor à ideia do agente que produz a mensagem, o que amplia as possibilidades de circulação com o respaldo de um profissional da saúde. O discurso pautado pela autorreferência técnica se repete no vídeo "Coronavírus - excelentes notícias", de 26 de maio de 2020 , em que o mediador cita estudo sem a referência do autor ou da instituição de pesquisa, recorrendo ao divisionismo como estratégia narrativa para rebater evidências científicas sobre a ineficácia do medicamento e sugere que há interesses econômicos e/ou políticos envolvidos.

[...] Carlos diz: acreditando que com o uso da hidroxicloroquina teremos uma melhora significativa até sair a vacina. Eu também acho. É o que a gente tem. (LIMA, 2020, s. p.).

[...] A hidroxicloroquina não tem patente. É gratuito...você não paga royalties pra ninguém não [...] não vou nem entrar no mérito da vacina, 
tá? Tô entrando no mérito do medicamento [...] aí você vem com uma hidroxicloroquina, você pode vir com uma ivermectina, com uma annita $^{5}$ e você resolver um problema [...] (LIMA, 2020, s. p.).

A relação do quadro "risco e incerteza científica" com a ideia de vacina como ameaça à saúde não ocorreu em vídeos desse corpus que misturam informações corretas, incorretas e/ou imprecisas. Nesse grupo de vídeos, o frame foi acionado em função de narrativas sujeitas a interpretações ambíguas e precipitadas, que podem confundir a audiência e comprometer as medidas de proteção, a exemplo da discussão sobre a imunidade adquirida pela infecção por coronavírus. Entretanto, os efeitos adversos das vacinas foram apontados como algo normal de ocorrer. No vídeo "Coronavírus - vacina oral tem data para começar", de 12 de abril, o médico admite que o conhecimento científico não está atrelado à certeza, ao mesmo tempo em que considera pouco provável a possibilidade de reinfecção. Em outro vídeo, "Coronavírus - promessa de uma nova vacina", de 14 de abril de 2020, a probabilidade se repete quase como uma certeza, sustentada na opinião e experiência do mediador como médico.

[...] Por isso que todo mundo que já teve a doença está curado e não vai ter a doença de novo. Ah, mas doutor, eu escutei falar que tem pessoal que tá pegando a doença de novo. Cara, eu acho isso muito pouco provável (LIMA, 2020, s. p.).

Ainda que faça a ressalva de que não havia evidências no momento de produção do vídeo, o mediador não contribui com uma informação precisa e cautelosa para evitar a desordem informacional. Afinal, as pesquisas sobre o novo vírus não eram conclusivas a esse respeito no início da pandemia, e os vídeos continuam disponíveis na plataforma, mesmo hoje quando já está comprovado que há casos de reinfecção e ainda não se sabe quanto tempo dura a proteção para quem já tomou a vacina.

Em menor ocorrência, o frame "sociocultural e ambiental" é acionado para propagar uma perspectiva de imunidade natural, que pode confundir e atrapalhar condutas de proteção contra a COVID-19, argumento também usado nos discursos antivacina. No vídeo “VACINA CONTRA A COVID-19?”, publicado em 29 de junho, a Dra. Lorena

5 Annita é o nome da marca de um antiparasitário que foi defendido pelo governo federal como um remédio promissor no tratamento da COVID-19 no início da infecção, cujas evidências científicas já demonstraram não ter efeito para a doença. 
Velho relaciona a falta de vitamina D ao número de mortes por COVID-19, apresentando resultados de estudos sem consenso científico e/ou conclusivos a respeito do assunto. Ainda que comprovadamente a vitamina $\mathrm{D}$ traga benefícios à saúde, a narrativa sugere uma espécie de vacina natural com a exposição ao sol para aumentar a imunidade, o que pode influenciar interpretações equivocadas de que a vitamina $\mathrm{D}$ funcione como medida de proteção contra o coronavírus. A desinformação também se manifesta no frame "sociocultural e ambiental" pela crença religiosa, como ocorre no vídeo do mediador Eduardo Sabbag, do canal Espiritismo Raiz, publicado em 27 de dezembro de 2020, que recomenda a vacina e revela já ter se exposto ao vírus sem ser infectado porque está protegido pelos espíritos. Essa mistura de intencionalidades incoerentes e paradoxais expõe a complexidade do fenômeno da desinformação e a importância de atores que atuem de forma mais efetiva no combate às dúvidas provenientes de rumores, boatos e mentiras sobre as vacinas.

\section{Narrativas de enfrentamento à desinformação}

A expectativa em torno da produção de uma vacina contra a COVID-19 e de sua eficácia conduziu narrativas de diferentes influenciadores, que deram explicações técnicas, desconstruindo dúvidas e medos sobre as vacinas. O frame "novo desenvolvimento tecnológico" foi predominante no conjunto dos vídeos dessa amostra, acionado por mediadores especialistas e não especialistas da área, a partir de expressões frequentes como "testes", "ensaios clínicos", "fase de testes", "eficácia", "eficaz", "resposta imunológica" e "produção em massa", que são alguns dos dispositivos desse enquadramento de narrativas sobre os resultados dos testes realizados em voluntários por diversos laboratórios e centros de pesquisa, as metodologias utilizadas na produção, bem como o nível de proteção alcançado e as previsões de entrega da nova tecnologia para vacinação em larga escala.

Apesar da liderança de profissionais da medicina na produção de vídeos sobre o tema, são os pesquisadores/professores e, principalmente, os youtubers divulgadores científicos que mais contribuíram para o enfrentamento de boatos e mentiras que circularam nas mídias sociais. O vídeo "Vacina Coronavac contra coronavírus: Quem tomou e o que aconteceu?", do professor e cientista da Unesp/Marília, Vítor Engrácia 
Valenti, publicado em 19 dezembro de 2020, traz resultados de testes e efeitos adversos observados na fase dois dessa vacina, numa narrativa que reconhece o receio que muitas pessoas têm sobre a vacina produzida na China, mas ressalta que efeitos adversos ocorrem com qualquer vacina. Dessa forma, associa os frames "novo desenvolvimento tecnológico" e "risco e incerteza científicas" para combater a desinformação, utilizando a conexão entre as evidências científicas e uma experiência bem-sucedida com vacina desenvolvida pelos chineses.

[...] A Sinovac foi a mesma entidade que está desenvolvendo a CoronaVac e que desenvolveu a vacina h1n1 e até o momento não vimos nenhum efeito grave da h1n1[...] Você já tomou vacina no braço? Doeu? É essa a reação adversa mais comum... efeitos adversos em vacina acontecem [...] (VALENTI, 2020, s. p.).

A eficácia, segurança e durabilidade da vacina centralizaram os questionamentos nas narrativas que se preocuparam em explicar os riscos e incertezas na produção de uma vacina, do ponto de vista científico. A maioria dos mediadores se mostrou otimista e favorável à medida que os avanços eram divulgados nas etapas 1, 2 e 3 de desenvolvimento. Porém, apenas vídeos de pesquisadores e divulgadores da ciência explicaram sobre a quarta fase, silenciada pela maioria dos mediadores. A ideia desse tipo de agente é esclarecer as etapas da produção de conhecimento em torno da vacina, pontuando que riscos e falhas são inerentes ao processo científico, assim como os níveis de proteção que podem ser alcançados ou não quando a pessoa for imunizada.

A produção de youtubers divulgadores da ciência tem o diferencial da performance audiovisual, compreendida aqui como os recursos de edição de imagem e som na construção da narrativa. No entanto, a maioria dos vídeos que compõem essa amostra explorou pouco esses recursos, geralmente limitada a cenários caseiros - quarto, sala de estar, fundo neutro sem marcas ou referências do canal -, cenários virtuais com uso de chroma key e recursos gráficos na identificação do mediador, fontes e reforçando a interação com textos que lembram a audiência para se inscrever no canal, dar likes, fazer comentários e compartilhar. Nesse quesito, os vídeos de youtubers divulgadores da ciência se destacam pela linguagem mais coloquial, o que facilita a compreensão da audiência não especializada, além de ilustrações animadas, infográficos, metáforas e 
analogias. Entre os 10 vídeos de divulgadores científicos deste estudo, oito são do canal Olá Ciência! e estão entre os vídeos com maior engajamento sobre vacina em 2020. Esse agente atuou diretamente contra mentiras espalhadas sobre a vacina contra a COVID-19 que utiliza a tecnologia do RNA mensageiro. O vídeo "VACINA da PFIZER para COVID: RISCO de ALTERAÇÃO GENÉTICA??”, publicado em 12 de dezembro de 2020 e que ocupa a sexta posição em engajamento (253.349 mil) comemora a aprovação da primeira vacina contra a COVID-19 de RNA aprovada no mundo. O frame "novo desenvolvimento tecnológico" é acionado para informar sobre as características, resultados e método da nova vacina. Enquanto o enquadramento secundário, “antecedentes/background" é sinalizado em recapitulações do mediador para explicar que o processo cientifico de produção do imunizante não é recente, mas resultado de um acúmulo de conhecimento. A explicação didática, ilustrada com imagens, mostra que o RNA mensageiro atua sem passar pelo núcleo da célula e, portanto, não tem fundamento dizer que provoca alteração genética.

[...] as pesquisas com essas vacinas de RNA já começaram há mais ou menos 30 anos pra outros vírus e doenças [...] então, quando alguém fala que esse tipo de vacina nunca foi testado em humanos, que a gente vai ser cobaia, essas coisas, essa pessoa não sabe nada de vacina (OLÁ CIÊNCIA!, 2020, s. p.).

O uso do frame "antecedentes/background" foi mais presente nas narrativas de divulgadores científicos para dar suporte aos esclarecimentos, principalmente em temas que necessitavam de explicações mais abrangentes sobre a vacina e suas técnicas ao longo do tempo. Apesar dos benefícios de proteção coletiva demonstrados na erradicação e no controle de várias doenças, o repertório do discurso antivacina se atualiza com desinformação sobre o RNA mensageiro e repete velhas teorias recorrentes em narrativas religiosas, como a do microchip para controle da população mundial, que agora ganha a versão de marca da besta na vacina contra a COVID-19.

Outros perfis de influenciadores contribuíram no combate à desordem informacional nas mídias sociais, de forma menos didática e técnica, mas rebatendo argumentos de negacionistas da pandemia que prejudicam a aceitação da vacina e a vacinação. É o caso do vídeo do canal Galãs Feios, intitulado “Bolsonminios não querem 
tomar vacina contra covid", publicado em 3 de setembro de 2020, no qual o mediador une crítica e humor para explicar o que considera o modus operandi bolsonarista de propagar desinformação sobre a vacina nas redes sociais. A narrativa evidencia o enquadramento "bioético e/ou jurídico" associado ao quadro "política pública e estratégia política" quando questiona declarações e condutas de atores políticos, como o presidente, que provocam desconfiança e desestimulam as pessoas a se vacinarem contra a COVID-19. De um modo geral, as narrativas desses mediadores defenderam a ideia de que vacinas são tecnologias desenvolvidas para salvar vidas e os benefícios superam os riscos quando o coletivo se sobrepõe ao individual, às opiniões pessoais ou disputas políticas.

\section{Considerações finais}

A desordem informacional presente nas narrativas do YouTube sobre a vacina contra a COVID-19, durante o seu desenvolvimento no ano de 2020, demonstra que os sentidos interpretativos disseminados pelos mediadores, com ou sem intenção de causar danos, associa vacina à ideia de ameaça à saúde pública e coloca o imunizante no centro de discussões políticas, seja sobre a obrigatoriedade ou não de tomar ou ainda na defesa da hidroxicloroquina como alternativa às vacinas. Os quadros "risco e incerteza científica" e "política pública e estratégia política" reforçaram a hesitação vacinal pela exploração dos sentimentos de medo, insegurança e desconfiança em relação à efetividade e necessidade de vacina enquanto estratégia de prevenção da doença e controle da pandemia. No embaralhamento entre informações corretas, erradas e/ou imprecisas, o que pode ocorrer numa mesma narrativa, há vídeos de diferentes perfis: médicos, religiosos, youtubers, profissional da comunicação, youtuber de humor e/ou comédia. Os vídeos de mediadores médicos, além de lideraram as narrativas sobre a vacina contra a COVID-19, também se destacaram nas ocorrências de desinformação ao validarem informações não comprovadas pela ciência, embora, paradoxalmente, divulgassem resultados de estudos e avanços científicos no desenvolvimento da vacina, muitas vezes sem referenciar a fonte da informação.

Na contramão dessa desordem informacional, youtubers divulgadores científicos e pesquisadores/professores ligados às universidades aderiram ao frame "novo desenvolvimento tecnológico" não apenas para defender a importância da vacina, mas 
como ação de enfrentamento à desinformação, explicando as etapas de desenvolvimento, situando a incerteza como algo inerente à produção do conhecimento, munindo a audiência com informações para compreender que os benefícios de uma vacina tornam os riscos aceitáveis, principalmente em relação à proteção coletiva. Essa discussão foi incorporada às narrativas vinculadas às evidências científicas de que uma ampla cobertura vacinal depende de ações do Estado para garantir distribuição e acesso à vacina. São sentidos interpretativos que decorrem da ação comunicativa entre agentes que, apesar de acionarem os mesmos quadros associados à desinformação, fazem recomendações distintas. Os resultados indicam que os rastros da desinformação exigem o fortalecimento de produções de influenciadores divulgadores da ciência que, ao ofertarem um repertório de informações confiáveis, ajudem os cidadãos a tomarem decisões que impactem na saúde pública e na sua qualidade de vida.

\section{Referências}

BALL, P. The epidemiology of misinformation: The disturbing story of how the web is weaving weird connections between hippies, Nazis, Russian agents and the rest of us to spread lies about Covid-19. Prospect. 2020.Disponível em: https://www.prospectmagazine.co.uk/science-andtechnology/epidemiology-misinformation-coronavirus-covid19-conspiracy-theory. Acesso em: 21 mai. 2021.

BASTOS, Pablo Nabarrete. Dialética do engajamento: uma contribuição crítica ao conceito. MATRIZes, v. 14, nº 1 jan/abr. 2020. p.193-220, São Paulo - Brasil. Disponível em: https://www.revistas.usp.br/matrizes/article/view/157540. Acesso em: 10 set. 2021.

BETETI, Fernando. Vacina Covid em menos de 1 ano? Dr. Alessandro Loiola e Fernando Beteti (vídeo - 2’38”). YouTube, 14/08/2020. Disponível em:

https://www.youtube.com/watch?v=u8Bb0V6p9-0.

BETETI, Fernando. Porque o Brasil é escolhido para testar vacina do COVID? Boletim Repórter Saúde - Fernando Beteti (vídeo - 29’26”). YouTube. 28/09/2020. Disponível em: https://www.youtube.com/watch?v=BuJhLDiGZIs.

BOLLMANN, S., D. Cook, J. Dumas, J. Fox, J. Josse, O. Keyes, C. Strobl, H. Turner, and R. Debelak. A first survey on the diversity of the R community. R Journal, 9:541-552, 2017. Disponível em: https://journal.r-project.org/archive/2017-2/forwards.pdf. Acesso em: 10 set. 2021.

BROTAS, A. et al. Discurso antivacina no YouTube: a mediação de influenciadores. Reciis Revista Eletrônica de Comunicação, Informação \& Inovação em Saúde, Rio de Janeiro, v. 15, n. 1, p.72-91, jan./mar, 2021. Disponível em:

https://www.reciis.icict.fiocruz.br/index.php/reciis/article/view/2281. Acesso em: 10 mar. 2021. 
DOUG VLOGS. URGENTE! BOLSONARO DECLARA ISSO SOBRE VACINA PARA COVID BRASIL PRECISA SABER E DESAFIO AMENDRONTA! (vídeo - 20’32”). YouTube. 29/09/2020. Disponível em: https://www.youtube.com/watch?v=RyRjnQlLUXg.

DOUG VLOGS. URGENTE! LUCIANO HUCK REBATE BOLSONARO BRASILEIROS PRECISAM SABER DISSO SOBRE VACINA COVID! (vídeo - 11'40”). YouTube, 04/09/2020. de setembro de 2020. Disponível em: https://www.youtube.com/watch?v=bveNAlnOCEY.

ENDERS, A. et al. 2020. The different forms of COVID-19 misinformation and their consequences. Harvard Kennedy School. Disponível em: https://misinforeview.hks.harvard.edu/article/the-different-forms-of-covid-19-misinformationand-their-consequences. Acesso em: 8 mai. 2021.

ENTMAN, R. M. Framing: Toward Clarification of Fractured Paradigm. Journal of Communication, 43(4):51-58, 1993. DOI: http://dx.doi.org/10.1111/j.14602466.1993.tb01304.x. Acesso em: 10 set. 2021.

ESPIRITISMO RAIZ - Eduardo Sabbag. [VACINA Covid -19 Vai Curar? Pode Tomar? Os Espíritos Me Falaram! Espiritismo Eduardo Sabbag]. (vídeo - 8’44”). YouTube. 27/12/2020. Disponível em: [https://www.youtube.com/watch?v=lEMiourv3Pc].

FREELON, D., \& WELLS, C. Disinformation as political communication. Political Communication, 37(2), 145-156, 2020. DOI: https://doi.org/10.1080/10584609.2020.1723755. Acesso em: 10 set. 2021.

FREIRE, Kel. Os signos tomando vacina do covid (vídeo - 6'49"). YouTube, 29/12/ 2020. Disponível em: https://www.youtube.com/watch?v=CLVFopZ9xiY.

GALÃS FEIOS. Bolsominions não querem tomar vacina contra covid | Galãs Feios (vídeo 14'53"). YouTube, 03/09/2020. Disponível em: https://www.youtube.com/watch?v=IU_Bspw2WIE.

GAMSON, W.; MODIGLIANI, A. Media discourse and public opinion on nuclear power: a constructionist approach. The American Journal of Sociology. Vol. 95, n. 1, p. 1-37, 1989.

GROHMANN, Rafael. A Noção de Engajamento: sentidos e armadilhas para a pesquisa em comunicação. Revista Famecos, Porto Alegre, v. 25, n. 3, p. 1-17. 2018. DOI: http://dx.doi.org/10.15448/1980-3729.2018.3.29387.

LATOUR, B e WOOLGAR, S. A vida de laboratório: a produção dos fatos científicos. Rio de Janeiro: Relume Dumará, 1997.

LATOUR, B. Ciência em Ação: como seguir cientistas e engenheiros sociedade afora. São Paulo: Editora Unesp, 2000.

LIMA, Marcelo Lima. Coronavírus - Nova Vacina em Teste - com Dr. Marcelo Lima (vídeo 1h 25'59"). YouTube, 24/04/2020. Disponível em: https://www.youtube.com/watch?v=bRz1dfbKMc0. 
LIMA, Marcelo Lima. Coronavírus - Vacina Oral Tem Data Para Começar - Dr. Marcelo Lima (vídeo - 29’01”). YouTube, 12/04/ 2020. Disponível em:

https://www.youtube.com/watch?v=QAHG5_CEg88.

LIMA, Marcelo Lima. Coronavírus: Excelentes Notícias - Dr. Marcelo Lima (vídeo - 44’04”). YouTube, 26/05/2020. Disponível em: https://www.youtube.com/watch?v=WtLsWINqACM.

LIMA, Marcelo. Coronavírus - Promessa de Uma Nova Vacina - Dr. Marcelo Lima (vídeo 31'57'). YouTube, 14/04/2020. Disponível em:

https://www.youtube.com/watch?v=ibNaEP1Be5s.

OLÁ, CIÊNCIA! VACINA da PFIZER para COVID: RISCO de ALTERAÇÃO GENÉTICA?? (vídeo - 11'29"). YouTube, 12/12/2020. Disponível em:

https://www.youtube.com/watch?v=KOu4jNnnl4k.

POSELLA, Lamartine. ISRAEL DESCOBRIU A CURA PARA O CORONAVÍRUS?| Anticorpo e Vacina | Lamartine Posella. (vídeo - 6'57'). YouTube, 07/05/2020. Disponível em: https://www.youtube.com/watch?v=TkVMHZ8ctCc.

R Core Team. R. A language and environment for statistical computing. R Foundation for Statistical Computing, Vienna. Disponível em: https://www.R-project.org. Acesso em: 10 set. 2021.

REESE, S. The Framing Project: A Bridging Model for Media Research Revisited. Journal of Communication, Oxford, v.57, p.148-154, 2007.

REESE, S. Prologue - framing public life: A bridging model for media research. In: REESE, S. D.; JR, O. H. G.; GRANT, A. E. (Eds.). Framing public life: perspectives on media and our understanding of the social life. New Jersey: Lawrence Erlbaum Publishers, p.7-31, 2001.

RICARD, J., MEDEIROS, J. Using misinformation as a political weapon: COVID-19 and Bolsonaro in Brazil. The Harvard Kennedy School (HKS) Misinformation Review. v.1, n.1, Cambridge, april, 2020. Disponível em: https://dash.harvard.edu/bitstream/handle/1/42661741/final_brazil.pdf?sequence=1\&isAllowed =y. Acesso em: 5 jun. 2020.

SCUDELLARI, M. State of denial. Nat Med. 16, 248, 2010. DOI:

https://doi.org/10.1038/nm0310-248a. Acesso em 5 ago. 2019.

SWIRE-THOMPSON, B; LAZER, D. Public Health and Online Misinformation: Challenges and Recommendations. Annual Review of Public Health, 41:1, 433-451, 2020. Disponível em: https://www.annualreviews.org/doi/10.1146/annurev-publhealth-040119-094127. Acesso em: 5 dez. 2020.

USCINSKI et al. 2020. Why do people believe COVID-19 conspiracy theories?. Harvard Kennedy School, Disponível em: https://misinforeview.hks.harvard.edu/article/why-do-peoplebelieve-covid-19-conspiracy-theories/\#0. Acesso em: 15 dez. 2020. 
VALENTI, Vítor Engrácia. Vacina Coronavac contra coronavírus: Quem tomou e o que aconteceu? (vídeo - 11'45”). YouTube, 19/12/2020. Disponível em:

https://www.youtube.com/watch?v=rxfFyf7VbI4.

VAN GORP, B. The constructionist approach to framing: bringing culture back. Journal of Communication, 57 (1), p. 60-78, 2007.

VELHO, Lorena. VACINA CONTRA A COVID-19?|Dra. Lorena Velho. (vídeo - 3'52").

YouTube, 29/06/2020. Disponível em: https://www.youtube.com/watch?v=DdyOuZ3M6Lc

VRAGA, E; BODE, L. Defining Misinformation and Understanding its Bounded Nature: Using Expertise and Evidence for Describing Misinformation. Political Communication, 37:1, 136144, 2020. Disponível em:

https://www.tandfonline.com/doi/full/10.1080/10584609.2020.1716500?scroll=top\&needAcces s=true. Acesso em: 15 abr. 2021.

WARDLE, Claire; DERAKHASHAN, Hossein. Information disorder: Toward an interdisciplinary framework for research and policy making. Council of Europe Report. 27 set. 2017. Disponível em: http://bit.ly/InformationDisorderReport. Acesso em: 5 jul. 2020.

WANG, Y. et al. Systematic literature review on the spread of health-related misinformation on social media. Social Science and Medicine, v. 240: 1-12, 2019. Disponível em: https://www.sciencedirect.com/science/article/pii/S0277953619305465. Acesso em :10 fev. 2021.

ZAROCOSTAS, J. Como combater um infodêmico. The Lancet, 395 (10225), 676, 2020. 